\section{Impact of cataract surgery on visual acuity and subjective functional outcomes: a population-based study in Sweden}

\author{
Abstract \\ Purpose First, to determine the effects of \\ cataract surgery on subjectively experienced \\ visual function and visual acuity in a defined \\ population, at a specific frequency of surgery. \\ Secondly, to validate questionnaire data \\ regarding the visual function of cataract \\ patients.
}

Methods A prospective population-based investigation of the subjective visual functional and visual acuity outcomes of cataract surgery over a 1 year time interval at one institution was conducted. All operated cases $(n=459)$ were grouped into three levels of visual impairment, according to the preoperative visual acuities of their better eyes. Subjective reading, TV watching, distance estimation and ability to orientate in unfamiliar surroundings, before and after surgery, were assessed using selfadministered questionnaires. The subjective outcomes were related to the subjects' postoperative visual acuities. The statistical evaluations comprised analyses of variance, Yates'-corrected chi-squared tests, weighted kappa and correlation statistics.

Results The pre-operative subjective visual disabilities of the patients were significantly correlated with the pre-operative visual acuities of the patients' better eyes. There was an improvement in subjective reading ability, distance estimation and ability to orientate in unfamiliar surroundings for most patients at all three pre-operative visual acuity levels.

After surgery there was a stronger correlation between the subjective functional improvement and the increase in visual acuity for the operated eye than for the better eye. Conclusions An incidence of cataract surgery of 3.3 per 1000 population for the year the present study was conducted seems not to be an over-utilisation of resources. Irrespective of the visual acuity level before cataract surgery, the vast majority of patients gain better subjective visual function and better acuity after surgery. It is possible to gain valid information from cataract surgery patients using a short questionnaire.

Key words Cataract surgery, Outcome, Questionnaire, Visual acuity, Visual function

Age-related cataract constitutes the main surgical workload of ophthalmological services and the bulk of ophthalmic surgery waiting lists in Sweden. ${ }^{1}$ With an increasingly ageing population as well as earlier intervention justified by improved technique, the demand for this surgical intervention is expected to rise. ${ }^{2,3}$ The increasing rate of cataract extractions can only be justified by a substantial benefit for the patients. The ultimate goals of cataract surgery are to improve the patient's visual ability and quality of life as much as possible. To get a 'true' picture of a patient's visual impairment it is necessary to assess the subjective visual function in addition to the visual acuity. 4,5

Significant variation in the frequency of cataract extraction exists across different countries and regions. Variations in clinical practice have been recognised as a marker for possible under- or over-utilisation of resources and have led to the assumption that unnecessary cataract extractions are performed..$^{5}$ Regular assessment and audit of this common procedure is therefore necessary for the provision of an accessible and accurate surgical service to meet the demand.

This observational population-based study focused predominantly on an analysis of the characteristics and visual abilities of patients admitted for cataract surgery. The study was designed to assess the effects of cataract surgery in terms of improvement in visual acuity and change in subjectively experienced visual

\author{
E. Mönestam \\ L. Wachtmeister \\ Department of \\ Ophthalmology \\ Umeå University \\ S-901 85 Umeå, Sweden

\section{E. Mönestam, MD} \\ Department of \\ Ophthalmology \\ Umeå University \\ S-901 85 Umeå, Sweden \\ Tel: +46907851342 \\ Fax: +4690145997 \\ e-mail: \\ eva.monestam@ophthal.umu.se
}

Received: 9 November 1998 Accepted in revised form: 7 April 1999 
function, in a defined population at a specific frequency of surgery. The aim was also to validate information from a simple short-form questionnaire regarding subjective visual function and the ability to perform visual activities.

\section{Materials and methods}

Between 1 April 1992 and 31 March 1993, all patients with senile or presenile cataract who underwent cataract surgery with insertion of intraocular lenses (IOLs) at Norrlands University Hospital in Umeå, Sweden, were registered. The catchment area has a population of about 175000 people. Our population represents $2 \%$ of the population of Sweden. The proportion of elderly persons 70 years and older was $11.4 \%$, and $3.7 \%$ were 80 years and older. ${ }^{6}$ All cataract surgery on our population was performed at the University Clinic, as there are no other public or private operating eye clinics in the area. As a result of Swedish Health Care policy, patients do not cross county borders. There are also no large regional differences in general health, social conditions, support service and incidence of ocular co-morbidity in Sweden. The incidence of cataract surgery was 3.3 per 1000 population for the 1-year period studied. In Table 1 the incidence of cataract surgery related to age and sex is shown. The drop-out frequency was $8.9 \%(45 / 504)$ including and 5.7\% (27/477) excluding deceased patients. No significant differences in age and sex distributions were found between the drop-outs and the included cases. A total of 459 surgical events in 453 patients were finally included in the study. Three hundred and fifty-three cases $(77 \%)$ had surgery on their first eye and 106 cases $(23 \%)$ on their second eye. The observations made on a person's two eyes are generally not independent but often highly correlated. No correction for this possible bias was made, as only 6 patients $(1 \%)$ had surgery on both eyes during the period studied. Further details concerning the cohort studied, and a description of the drop-outs, have been published previously. $^{7}$

Informed consent was obtained from all subjects included. A few weeks before surgery the patients had a clinical eye examination including: refraction, visual acuity, tonometry, slit-lamp microscopy and ophthalmoscopy through a dilated pupil. Visual acuity (VA) for each eye was tested on a Monoyer letter chart, utilising the best refraction.

This study focuses on subjective visual function and ability in relation to pre-operative and post-operative visual acuities. It was therefore necessary to ascertain

Table 1. Incidence (per 1000 population) of cataract surgery in the population studied in relation to age and sex

\begin{tabular}{lcc}
\hline Age & Males & Females \\
\hline $50-59$ years & 1.0 & 1.7 \\
$60-69$ years & 4.9 & 6.2 \\
$70-79$ years & 11.4 & 18.0 \\
80 years and older & 22.6 & 31.8 \\
\hline
\end{tabular}

that patients were assigned to the correct VA level. Several patients had cataract in their fellow eyes and the refraction in cataractous eyes often changes. Therefore, before surgery the presenting VAs of the better eyes were also checked and corrected. Presenting VA was defined as the distance VA of the better eye with the correction worn by the patient or, if the patient did not use correction for distance, without spectacles.

Before surgery the patients were categorised into one of three levels of visual impairment according to the distance acuity with best correction of the better eye. The following grading system was used:

VA level I: 'Good acuity'. Decimal acuity better than 0.5 (> 20/40).

VA level II: 'Moderate acuity'. Decimal acuity between 0.2 and $0.5(20 / 100-20 / 40)$.

VA level III: 'Low acuity'. Decimal acuity less than 0.1 (20/200 or worse).

Level I represents objectively essentially no or mild visual acuity limitation. Level II stands for objectively a moderate impairment with useful visual acuity but mostly not good enough for driving. Level III represents objectively severe visual impairment and equals the US criteria for legal blindness.

A few days before surgery a questionnaire was mailed to each patient. On the day of surgery the questionnaire was delivered by the patient to the nursing staff of the Eye Clinic. The nurses involved were specially trained to check that the questionnaire had been understood and completely answered. The questionnaire was intentionally short and made as simple as possible to achieve a high response rate and less selection bias from this elderly population. Earlier research has shown that there is good potential in using short-form health measures in surveys. ${ }^{8}$ The questions were similar to those in other well-validated studies of visual function. ${ }^{5,9,10}$ Patients were asked to give a self-report on vision-dependent activities such as reading, TV watching and orientating in unfamiliar surroundings. The questions analysed in this paper are listed in Table 2.

The type of surgery performed was a standard extracapsular cataract extraction (ECCE) in 390 cases (85\%; 299 first eyes and 91 second eyes), phacoemulsification (PE) in 57 cases (12\%; 47 first eyes and 10 second eyes) and intracapsular cataract extraction (ICCE) in 12 cases (3\%; 7 first eyes and 5 second eyes). The complication rates concerning zonular/posterior capsular rupture with or without vitreous loss were $5.6 \%$ for ECCE and 3.5\% for PE. Most of these complications were of a small extent. Only 2.6\% (12/447) of all ECCE and PE cases received an anterior chamber IOL.

Two to three months after surgery the patients' records were studied to obtain information about the best corrected monocular VA and refraction of both eyes. It was ensured that the operated eye had healed, vision had stabilised and that spectacles had been prescribed if necessary. One to two months after the patients had received their prescription spectacles, a second questionnaire similar to the first one was mailed to them 


\section{Before surgery}

Can you read ordinary newspaper-size print? (Yes/No)

If yes, what visual aids do you need to be able to read?

(None/Spectacles/Hand-held or stand magnifiers/Others; please specify)

Do you experience any visual problems while watching TV due to your cataractous eye? (Yes difficulties/No)

Do you experience difficulties when orientating in unfamiliar surroundings? (No problems/Some problems/Severe problems)

Do you experience difficulties in estimating distance? nearby (e.g. pouring a cup of coffee) (Yes/No) far away (eg while driving (drivers) or in other 'traffic situations') (Yes/No)

\section{After surgery}

Has your reading ability changed beause of your eye surgery? (Better/No change/Worse)

Has your TV-watching ability changed because of your eye surgery? (Better/No change/Worse)

Has your ability to orientate in unfamiliar surroundings changed because of your eye surgery? (No problems before surgery/Worse/No change/Slightly better/Much better)

Do you experience difficulties in estimating distance? nearby (e.g. pouring a cup of coffee) (Yes/No) far away (e.g. while driving (drivers) or in other 'traffic situations') (Yes/No)

Has your eye surgery changed your ability in the activities of daily life? (For the worse/No change/Slightly improved/Much improved)

(Table 2). This delay was intentional to give the patients the time necessary to adjust to their new spectacles. The mean time lapse from date of surgery to when the second questionnaire was returned was 5.3 (SD 1.8) months.

\section{Statistical methods}

To evaluate changes in VAs the decimal acuity values were converted into a log scale using the method outlined by Holladay and Prager. ${ }^{11}$ The range of VAs includes acuities such as counting fingers (CF) and hand movements (HM). The following arbitrary logMAR (minimum angle of resolution) values have been used by other authors: $\mathrm{CF}$ in front of the eye $=\log \mathrm{MAR} 2.2$, $\mathrm{HM}=\log \mathrm{MAR} 2.3$, and light perception $(\mathrm{P})=\log \mathrm{MAR}$ 2.5. ${ }^{10,12}$ To define changes in VAs, logMAR acuities before surgery were subtracted from logMAR acuities after surgery. For example: VA before surgery $=\log$ MAR 1 (decimal acity 0.1 ) and after surgery $=$ logMAR 0.7 (decimal acuity 0.2), results in an improvement of $1-0.7=0.3 \operatorname{logMAR}$ units. Consequently, a worse VA after surgery was indicated by a negative value.

Mann-Whitney $U$-tests were used to compare the visual acuities before and after surgery of the operated eyes in each VA-level group, separately. Non-parametric one-way analyses of variance (Kruskal-Wallis tests) were used to compare the differences between the three groups of visual functional levels regarding VAs before and after surgery, disability indices and improvement indices. One-way analysis of variance was used to compare age differences. Yates' corrected chi-squared tests were used to analyse the two-by-two and two-bythree frequency tables. Weighted kappa statistics were used to compare ordinal data. ${ }^{13}$ To calculate correlations, Spearman's rank $\left(r_{\mathrm{S}}\right)$ corrected for ties and single measure intra-class correlations were used.

\section{Disability index}

A numerical summary of the patients' subjective visual disability before surgery was created from each questionnaire as follows: $\mathrm{A}$, reading ability $(1=$ with ordinary presbyopic spectacles up to addition +4 , 2 = only with hand-held or stand magnifiers, $3=$ only with Magnivision, $4=$ (cannot read); B, TV watching ability $(1=$ no problems, 2 = yes, problems); $C$, orientation in unfamiliar surroundings $(1=$ no problems, 2 = some problems, 3 = large problems); D, distance estimation ( 1 = no problems nearby or far away, $2=$ problems nearby or far away, $3=$ problems for both nearby and far away). Disability index was calculated as the sum of $A+B+C+D$ (range 4-12). A large score denotes substantial visual disability.

\section{Improvement index}

After surgery a numerical summary of the patient's subjective improvement was made from each questionnaire as follows: $A$, reading ability $(1=$ worse, 2 = no change, 3 = better); $\mathrm{B}, \mathrm{TV}$-watching ability (scored as $\mathrm{A}) ; \mathrm{C}$, orientation in unfamiliar surroundings $(1=$ worse, $2=$ no change, $2.5=$ slightly better, $3=$ much better); D, distance estimation ( 1 = worse, 2 = no change, 3 = either near or far away distance estimation improved, $4=$ both near and far away distance estimation improved). Improvement index was calculated as the 
Table 3. Mean age, percentage of males, percentage of first eye and right eye surgery and median decimal acuity of the better eye and operated eye before and after surgery in each visual acuity (VA)-level group

\begin{tabular}{|c|c|c|c|}
\hline & $\begin{array}{l}\text { VA-level I } \\
(>20 / 40)\end{array}$ & $\begin{array}{c}\text { VA-level II } \\
(20 / 140-20 / 40)\end{array}$ & $\begin{array}{c}\text { VA-level III } \\
\text { (20/200 or less) }\end{array}$ \\
\hline No. & 211 & 206 & 42 \\
\hline Mean age (years) & $71.2^{*}$ & 77.1 & 77.1 \\
\hline Males (\%) & 36 & 32 & 33 \\
\hline Surgery on first eye (\%) & 71 & 82 & 81 \\
\hline Surgery on right eye (\%) & 54 & 51 & 52 \\
\hline \multicolumn{4}{|c|}{ Median decimal acuity (range) } \\
\hline \multicolumn{4}{|l|}{ Before surgery } \\
\hline Eye to be operated & $0.06(\mathrm{P}-0.5)$ & $0.1(\mathrm{P}-0.5)^{* *}$ & $0.015(\mathrm{P}-0.1)$ \\
\hline Better eye & $0.8(0.6-1.0)$ & $0.4(0.2-0.5)$ & $0.1(P-0.1)$ \\
\hline \multicolumn{4}{|l|}{ After surgery } \\
\hline Operated eye & $0.8(0.02-1.0)^{* * *}$ & $0.6(\mathrm{HM}-1.0)^{* * *}$ & $0.4(\mathrm{HM}-1.0)^{* * *}$ \\
\hline
\end{tabular}

Ranges of VA values are within parentheses. P and HM refer to perception of light and hand movements, respectively. *Significantly lower mean age in group I compared with groups II and III ( $p<0.0001$ and $p<0.001$, respectively). **Significantly better VA of the eye to be operated in patients of group II compared with groups I and III ( $p<0.00001$, respectively). ***Significantly improved median decimal acuity of the operated eye after surgery $(p<0.00001)$.

sum of $A+B+C+D$ (range 4-13). A high score denotes a subjectively larger improvement in visual ability to perform visually-dependent tasks.

\section{Validation}

The test-retest reliability of our questionnaires was measured from independent samples of elderly cataract patients before and after surgery $(n=24)$, respectively. The mean interval between the test and retest questionnaires was 11.5 days $(\mathrm{SD}=5.3)$. Weighted kappa statistics for the questions analysed in the study ranged between 0.41 and 1.0. The reliability of the disability and improvement indices were estimated by separately calculating the Spearman correlation coefficients, and found to be $r_{\mathrm{s}}=0.88$ and $r_{\mathrm{s}}=0.84$, respectively. Intraclass correlation coefficients were 0.84 (95\% CI 0.61-0.91) and 0.81 (95\% CI 0.59-0.92). Valid information concerning performance of everyday tasks dependent on vision can be obtained using questionnaires. ${ }^{14}$ The activities highlighted by the questionnaire were either known from other published reports as difficult to perform by patients with cataract and visual impairment, or were chosen from our clinical experience. ${ }^{10,15}$

Validity was assessed in the same way as used in previous studies of cataract surgery outcome. ${ }^{10,16}$ The Spearman correlation coefficient was determined between the pre-operative disability index and preoperative measures of VA of the better eye or the eye to be operated on. The validity of the improvement index was evaluated in two ways: first by calculating the correlation between the improvement index and the subjective change of daily life experienced by each patient after surgery, and second by assessing the correlation between the improvement index and the post-operative change in VA of the operated eye and better eye, respectively.

\section{Results}

\section{Demographics}

The characteristics of the patients in the three VA-level groups are shown in Table 3 . The patients with good acuity (level I) were significantly younger than those in the two other groups (71.2 and 77.1 years; $p<0.001$ (level III) and $p<0.0001$ (level II), respectively). The proportion of males was slightly larger in the good acuity group compared with the other groups but this difference was not significant. A significantly greater proportion of patients $(29 \%)$ with good acuity (level I) had had surgery on the second eye compared with the other patientgroups $(18 \%$ and $19 \%$, respectively; $p<0.05)$.

\section{Visual acuity}

Before surgery the median decimal acuity of the eyes to be operated on was significantly better in the moderate acuity group (0.1) compared with those of the low (0.015; $p<0.00001)$ and good acuity groups $(0.06 ; p<0.00001)$

(Table 3). The distributions of decimal acuities of the eyes to be operated before surgery in each visual acuity level group are shown in Fig. 1.

After surgery the visual acuity of the operated eye improved significantly in all groups $(p<0.00001)$ (Table 3). A post-operative decimal acuity of the

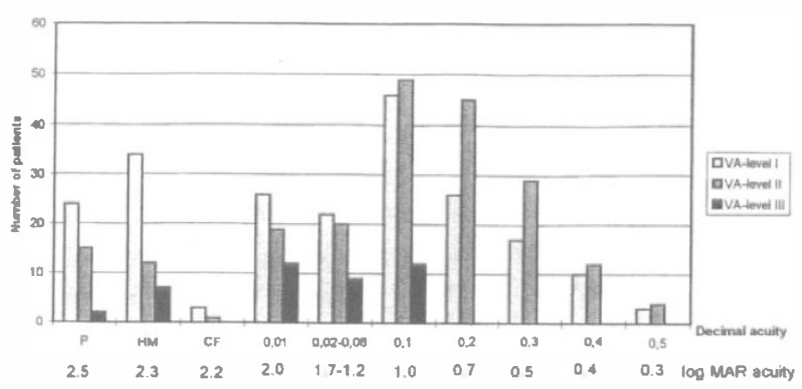

Fig. 1. Distribution of decimal and $\log M A R$ acuities of the eyes to be operated in the different VA level groups. P, perception of light; HM, hand movements; $C F$, counting fingers in front of the eye. 
Table 4. Visual acuity of the operated eye in relation to the visual acuity of the fellow eye in each VA-level group before and after surgery

\begin{tabular}{|c|c|c|c|c|c|c|}
\hline \multirow{2}{*}{ Before surgery } & \multicolumn{6}{|c|}{ Visual acuity of the operated eye } \\
\hline & \multicolumn{2}{|c|}{ Worse than fellow eye } & \multicolumn{2}{|c|}{ Equal to fellow eye } & \multicolumn{2}{|c|}{ Better than fellow eye } \\
\hline $\begin{array}{l}\text { VA-level I (\%) } \\
\text { VA-level II } \\
\text { VA-level III (\%) } \\
\text { All (\%) }\end{array}$ & $\begin{array}{c}211 / 211 \\
72 / 206 \\
20 / 42 \\
403 / 459\end{array}$ & $\begin{array}{r}(100 \%) \\
(84 \%) \\
(48 \%) \\
(88 \%)\end{array}$ & \begin{tabular}{l}
\multicolumn{1}{c}{0} \\
$15 / 206$ \\
$10 / 42$ \\
$25 / 459$
\end{tabular} & $\begin{array}{r}(7 \%) \\
(24 \%) \\
(5 \%)\end{array}$ & \begin{tabular}{l}
\multicolumn{1}{c}{0} \\
$19 / 206$ \\
$12 / 42$ \\
$31 / 459$
\end{tabular} & $\begin{array}{r}(9 \%) \\
(29 \%) \\
(7 \%)\end{array}$ \\
\hline $\begin{array}{l}\text { After surgery } \\
\text { VA-level I (\%) } \\
\text { VA-level II (\%) } \\
\text { VA-level III (\%) } \\
\text { All (\%) }\end{array}$ & $\begin{array}{c}79 / 211 \\
36 / 206 \\
2 / 42 \\
117 / 459\end{array}$ & $\begin{array}{r}(37 \%) \\
(18 \%) \\
(5 \%) \\
(26 \%) \\
\end{array}$ & $\begin{array}{c}56 / 211 \\
17 / 206 \\
7 / 42 \\
80 / 459 \\
\end{array}$ & $\begin{array}{r}(27 \%) \\
(8 \%) \\
(16 \%) \\
(17 \%) \\
\end{array}$ & $\begin{array}{c}76 / 211 \\
153 / 206 \\
33 / 42 \\
262 / 459\end{array}$ & $\begin{array}{l}(36 \%) \\
(74 \%) \\
(79 \%) \\
(57 \%)\end{array}$ \\
\hline
\end{tabular}

operated eye of less than $0.5(<20 / 40)$ was found in a significantly larger proportion of the patients at level III $(52 \% ; 22 / 42)$ compared with level II $(27 \% ; 55 / 206)$ and level I $(11 \% ; 24 / 211)(p<0.0001)$.

\section{Visual outcome analysis}

Initially, the VA of the eye to be operated was equal to or better than that of the fellow eye in only $12 \%$ of all the patients (Table 4). This proportion had significantly increased to $74 \%(p<0.00001)$ after surgery. Table 5 shows the changes in VA level after surgery. At VA level I only 4 patients ( $2 \%$ ) deteriorated in vision to level II after surgery. (Two patients had age-related macular degeneration of both eyes, 1 patient had a macular pucker causing subnormal vision in the operated eye and increasing cataract of the fellow eye, and 1 patient had progressive bilateral maculopathy as a result of diabetes.) Sixty-seven per cent $(138 / 206)$ of the patients in the moderate acuity group improved their VA levels. Twothirds of the patients at VA level III increased at least one level and only one-third remained at the same level.

\section{Presenting visual acuity}

Eleven per cent of the patients $(52 / 459)$ did not have optimal correction of their better eyes. However, only $1.5 \%$ of the patients $(7 / 459)$ had a presenting VA, that is everyday functional acuity, which would assign them to a lower VA level than with the best correction. Three patients would have been categorised as level II instead of level I and 4 patients as level III instead of level II. Corrections for these differences were not made as the results of the study would not have been significantly changed. Uncorrected refraction was defined as an improvement in the visual acuity of at least one Snellen line with an addition of \pm 0.5 dioptres spherical equivalence or more.

\section{Reading ability}

Fig. 2 show the subjective ability to read newsprint (N8) and the aids needed before and after surgery in the different VA-level groups, respectively. After surgery a significant decrease in number of patients who could not read was found in the pre-operative low and moderate acuity groups $(p<0.001)$. There was no significant change in the number of patients unable to read in the good acuity group as the patients had a VA of $>0.5$ in the better eye before surgery. However, one patient of level I stated an inability to read after surgery. The cause of this is unknown as the patient had received appropriate correction for near vision after surgery.

In all VA-level groups there were significantly larger proportions of patients who managed to read newsprint with ordinary presbyopic lenses or without reading aids after surgery compared with before surgery $(p<0.0005)$.

In Fig. 3 the subjective change in reading ability after surgery is shown. The patients with best VA of their better eyes before surgery stated, in a significantly higher proportion, improved reading ability ( $88 \%$ ) after surgery, compared with the patients in the VA-level II and III groups $(79 \%$ and $71 \%$ respectively; chi-squared for trend $p<0.01)$.

\section{Orientation in unfamiliar surroundings}

The percentage of patients and perceived degree of problems with orientating in unfamiliar surroundings before surgery in each VA-level group, are shown in Fig. 4a. A larger proportion of patients of VA-level III had problems before surgery compared with patients of the VA-level II and I groups (chi-square for trend $p<0.001)$. The changes in ability of orientating in unfamiliar surroundings after surgery in the different VA-level groups are shown in Fig. 4b. Eighty-three per cent of the level III patients (37/42) experienced much or somewhat improved orientation ability after surgery.

Table 5. Changes in VA level of the better eyes in relation to pre-operative VA level

\begin{tabular}{|c|c|c|c|c|c|}
\hline \multirow{3}{*}{$\frac{\text { Pre-operative level }}{\text { VA-level I (\%) }}$} & \multicolumn{4}{|c|}{ Post-operative level } & \\
\hline & \multicolumn{2}{|c|}{ VA-level I } & VA-level II & VA-level III & Total no. of patients (\%) \\
\hline & $207 / 211$ & (98) & $4 / 211$ & 0 & $211 / 211$ \\
\hline VA-level II (\%) & $138 / 206$ & (67) & $68 / 206 \quad(33)$ & 0 & $206 / 206$ \\
\hline VA-level III (\%) & $18 / 42$ & (43) & $10 / 42 \quad(24)$ & $14 / 42 \quad(33)$ & $42 / 42$ \\
\hline
\end{tabular}




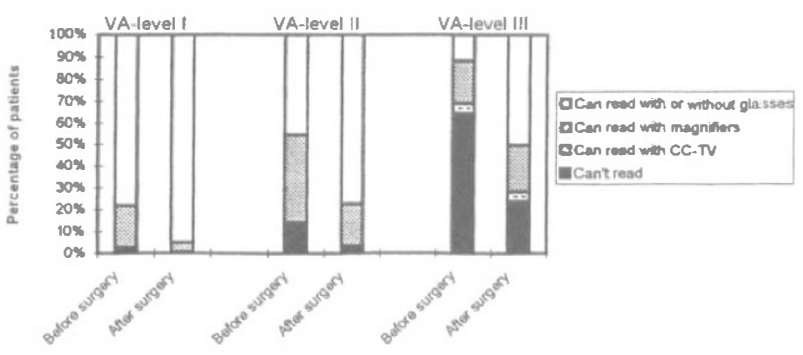

Fig. 2. Subjective ability to read newspaper-size print and the requirements necessary before and after surgery in the different $V A$ level groups, respectively.

A substantial proportion of the patients of level I (140/ $211 ; 66 \%$ ) also experienced improvement after surgery even though $29 \%(61 / 211)$ had no problems with their orientation ability before surgery.

\section{Distance estimation problems nearby and far away}

Fig. 5 shows the percentage of patients with distance estimation problems nearby and far away, before and after surgery. A significantly greater proportion of patients with low acuity $(33 / 42 ; 79 \% ; p<0.01)$ had distance estimation problems nearby before surgery compared with the patients of VA levels II $(100 / 206$; $49 \%)$ and I (115/211; 54\%). After surgery, at all three VA levels, a significantly reduced number of patients stated problems with distance estimation nearby and/or far away $(p<0.001)$ (Fig. 5). In all three VA groups there was a significantly greater proportion $(p<0.001)$ of patients with no distance estimation problems nearby or far away after surgery compared with before surgery.

\section{Subjective ability in the activities of daily life}

Table 6 shows the patients' experience of global change in their ability in the activities of daily life in relation to the improvement in VA of the better eye and operated eye, respectively. There was a statistically significant difference in improvement of VA for the operated eye as well as for the better eye among the four various groups stratified by subjective change in the activities of daily life $(p<0.005$ and $p<0.02$, respectively; Kruskal-Wallis test). The larger the improvement in VA (logMAR) of the operated eye and better eye, the greater was the experience of global improvement in their daily lives. There was also a highly significant correlation $\left(r_{\mathrm{s}}=0.62\right.$;

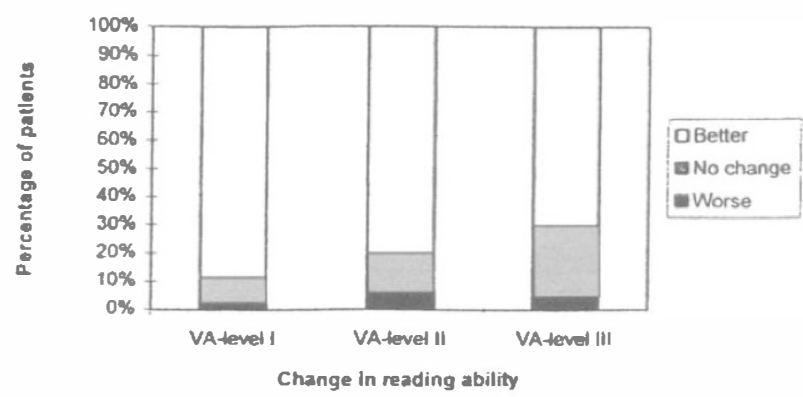

Fig. 3. Subjective change in reading ability in the different VA-level groups after surgery.
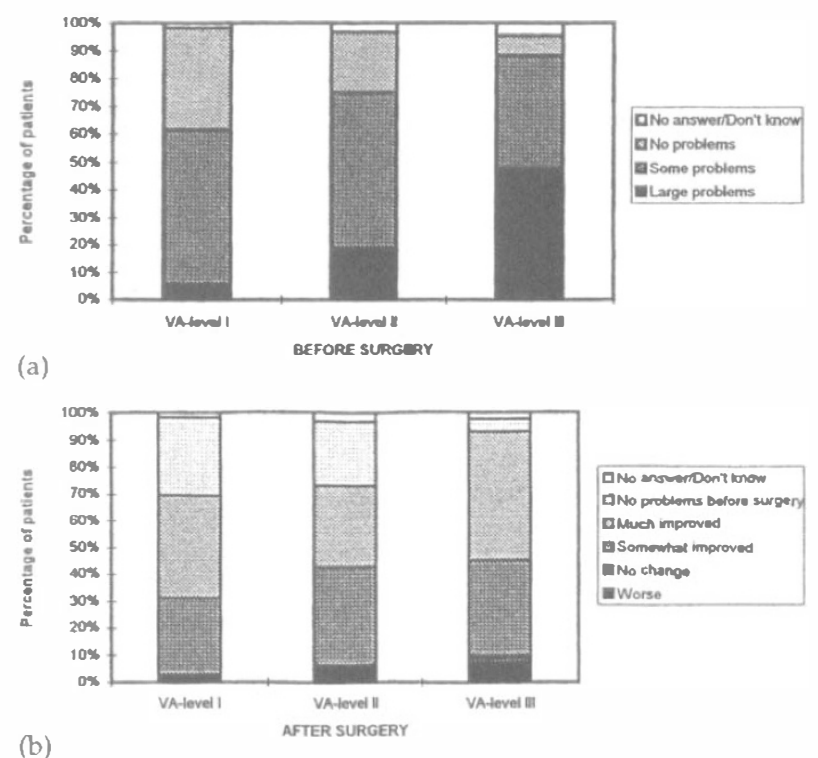

(b)

Fig. 4. (a) Percentage of patients and perceived degree of problems while orientating in unfamiliar surroundings in the different VA level groups before surgery. (b) Subjective change in orientating ability in unfamiliar surroundings in the different $V A$ level groups after surgery.

$p<0.0001$ ) between the improvement index and the patients' subjective change in ability in the activities of daily life due to their cataract surgery.

\section{Disability and improvement indices}

The patients in VA-level I group had a mean disability index of 6.6 (median 6; range 4-12), the patients at VA-level II, 7.6 (median 7.5; range 4-12) and those of VA-level III, 10.1 (median 10; range 6-12). These differences were statistically significant $(p<0.001$; Kruskal-Wallis test). The cumulative distribution of disability indices in the three VA-level groups are shown in Fig. 6.

There was also a statistically significant correlation between the VA of the better eye before surgery and the disability index $\left(r_{\mathrm{s}}=0.47 ; p<0.001\right)$ : the worse the acuity of the better eye the more pronounced subjective visual disability was experienced. No correlation was, however, found between the VA of the eye to be operated on and the disability index $\left(r_{\mathrm{s}}=0.03\right)$.

In the VA-level I group the mean improvement index was $10.9(\mathrm{SD}=1.5$; median $=11$; range $6-13)$, at VA-level II, $10.4(\mathrm{SD}=1.9$; median $=10.5$; range $4-13)$ and at VA-level III, 10.5 (SD = 2.1; median = 11; range 5-13). No statistically significant differences among the groups

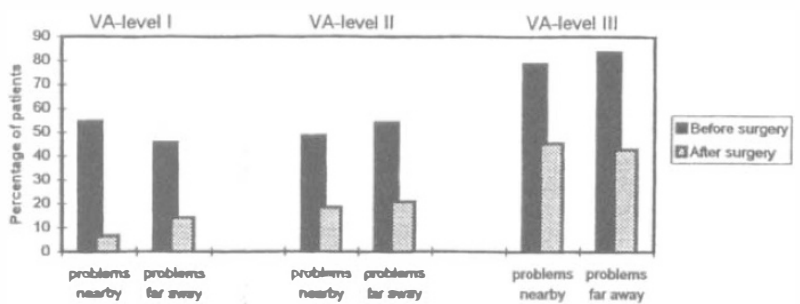

Fig. 5. Percentage of patients with distance estimation problems in the different VA-level groups before and after surgery, respectively. 
Table 6. Patients' experience of change in their ability in the activities of daily life in relation to improvement in VA for the operated eye and better eye, respectively

\begin{tabular}{lcc}
\hline \multirow{2}{*}{$\begin{array}{l}\text { Change in ability in the } \\
\text { activities of daily life }\end{array}$} & \multicolumn{2}{c}{ VA improvement $[\operatorname{logMAR}(\mathrm{SD})]$} \\
\cline { 2 - 3 } Much improved & Operated eye & Better eye \\
Slightly improved & $1.18(0.72)$ & $0.23(0.33)$ \\
No change & $0.97(0.72)$ & $0.21(0.27)$ \\
Worse & $0.47(0.79)$ & $0.12(0.29)$ \\
$p$ value & $<0.005$ & $0.18(0.45)$ \\
\hline
\end{tabular}

were found. The cumulative distribution of the improvement indices in the three VA-level groups is shown in Fig. 7.

There was a statistically significant correlation between the improvement index and the improvement of VA of the operated eye $\left(r_{\mathrm{s}}=0.27 ; p<0.0001\right)$. The correlation between the improvement index and the improvement of VA of the better eye after surgery was also statistically significant but of a smaller magnitude $\left(r_{\mathrm{s}}=0.16 ; p<0.001\right)$. This could probably be the result of 57 patients (12\%) having a VA of their fellow (better) eyes of $1.0(20 / 20)$ before surgery. In these cases a ceiling effect precludes the patients' ability to improve the VA of their better eyes after surgery. If the VAs of their operated eyes improve to $20 / 20$ these patients have by definition an improvement in VA of their better eyes of 0 $\log$ MAR units.

\section{Discussion}

In the present study improvement of at least one functional stage step was found to occur in $36 \%$ of all patients and loss of one functional step in only 4 patients (2\%). The majority of the study patients belonged to VA-levels II and III before surgery and $63 \%$ of these $(156 / 248)$ were found to reach VA-level I after surgery. The functional grading system used described essentially intact reading vision (VA-level I), reading vision only with difficulty (VA-level II) and ambulatory vision (VA-level III). Similar functional stages have been defined in a previous report concerning vitreous surgery. ${ }^{17}$ The majority (67\%) of the patients of VA-level III were found to improve to VA-level I or II. Thus, these patients had a marked functional improvement, as their

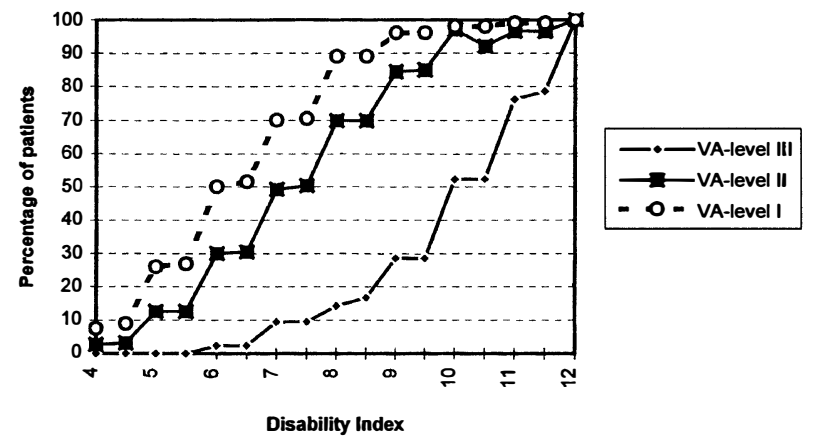

Fig. 6. Cumulative distribution of disability indices in the different VA-level groups. possibility of gaining reading vision with relatively simple reading aids thereby increased. On admission, 9\% of the cohort were found to be blind using the US criteria for legal blindness (better eye equal to $20 / 200$ or less). ${ }^{18}$ After surgery only 3\% (14/459) were found to remain legally blind. A substantial number $(262 / 459 ; 57 \%)$ of the operated eyes were found to become the eye with better visual acuity. Thus, the current study indeed demonstrates the significant value of cataract surgery. Furthermore, the implication of these findings is that several patients may even have benefited from earlier surgery, irrespective of whether surgery was conducted on the first or second eye.

A frequency of cataract surgery of 3.3 per 1000 population, which was the incidence during the year our study was conducted, might be an under-utilisation of resources regarding both the need and the demand for cataract surgery in the population concerned. The results of the present study do not make it possible to estimate the gap between the need and demand for surgery in our population. Future population-based studies with higher frequency of cataract surgery and consequently relatively higher frequency of second eye surgery are necessary to answer that question.

End-points such as subjective visual function after cataract surgery have proved to be at least as relevant as traditional clinical measures of success such as improvement in visual acuity. ${ }^{12,19}$ We found a statistically significant correlation between the improvement index and visual acuity of the operated eye and the better eye. That is, the larger the improvement in VA in the operated eye or better eye the more pronounced was the patient's experience of enhanced ability to perform the visually related tasks assessed in our study.

It is intuitively obvious that the value of successful surgery depends greatly on the visual status of the fellow eye. In addition, the possibility exists that increased scrutiny for cost-effectiveness may limit therapy based on such considerations. This means a reluctance to operate on a cataractous lens in patients with one good eye regardless of whether that eye has had cataract surgery or not. We found that irrespective of the preoperative visual acuity of the better eye, the vast majority of patients managed to achieve a good subjective as well as a good objective visual functional result. Also the

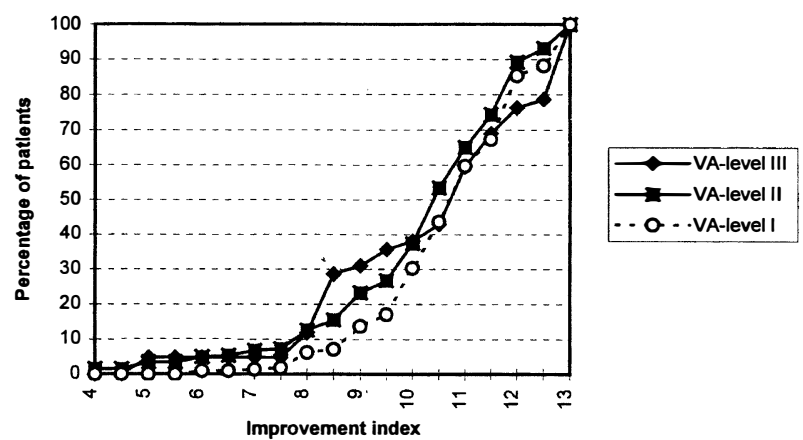

Fig. 7. Cumulative distribution of improvement indices in the different $V A$-level groups. 
patients with good (VA-level I) acuity of their fellow eye, including comparatively more second eyes to be operated, subjectively improved their visual function after surgery. This is probably a result of visual function being substantially reduced by binocular inhibition, glare and other problems related to a cataractous lens..$^{20,21}$ Moreover, Laidlaw and colleagues ${ }^{22}$ have recently shown the great value of second eye surgery. Thus, we conclude that the cataractous eye to be operated on in this study substantially contributes pre-operatively to perceived visual function. Irrespective of the visual acuity of the better eye before surgery, most patients experienced improvement in subjective and objective visual function after cataract surgery. Consequently, the decision to undergo planned cataract surgery and the appropriate timing should be based on the patient's subjective dissatisfaction with current visual function, in addition to objective findings by the ophthalmologist, rather than the visual acuity per se. ${ }^{5,23}$

The ability to perform many vision-dependent activities has been reported to be determined more by the vision of the better eye than the vision of the worse eye. ${ }^{10}$ As important or even more important than a patient's best corrected VA is that person's day-to-day functional vision. Uncorrected refractive errors can result in considerably worse functional vision than a person's best corrected vision. Therefore, in the present study the presenting visual acuity of the better eye of each patient was measured. We found that $11 \%$ could improve their visual acuity with new spectacles, which corresponds well with previous findings. ${ }^{14}$ Most studies of visual function relating to VA report best corrected acuity as we do and not presenting acuity. Therefore, no effort was made for correction in the few cases in our study.

Previous studies have shown that one-third of cataract patients have some coexisting ocular pathology present in the eye that had surgery. ${ }^{24}$ In the present study we found $22 \%$ not obtaining a post-operative VA of 0.5 $(20 / 40)$ or better, mainly as a result of age-related macular degeneration and glaucoma. These findings are in accordance with those of Lumme and Laatikainen. ${ }^{24}$ The issue of coexisting ocular pathology and its implications for visual functional results of the lowvision patients in our population have been reported in another paper. $^{25}$

Our results offer support for the validity of the study instrument. The visual abilities regarding reading, TV-watching, orientation ability, distance estimation nearby and far away and the two indices created were found to have the same magnitudes of validity as indices from more extensive questionnaires. ${ }^{5}$ In our study the correlations with measures of vision were also in the directions expected. The disability index and the VA of the better eye before surgery were found to be significantly correlated, which is consistent with the results of other studies. ${ }^{10,16}$ The highly significant correlation found between the improvement index and the subjective change in the patient's global ability in the activities of daily life is of a similar magnitude to that reported by Mangione et al. ${ }^{5}$ Substantial differences in reading ability, orientation ability and problems with distance estimation were observed between the groups of patients stratified by VA level. The pattern of differences was also consistent with previous studies. ${ }^{26,27}$ Thus, we conclude that the few rather simple questions used in our short-form questionnaire demonstrate validity of a similar magnitude as more extensive questionnaires.

In conclusion, a frequency of cataract surgery of 3.3 per 1000 population, as was found during the year the present study was conducted, seems not to be an overutilisation of resources. Our results show that irrespective of the pre-operative VA level of the better eye, there is an improvement in the subjective visual ability to perform everyday tasks that are dependent on vision, as well as an improvement in VA, in the majority of patients after cataract surgery. Secondly, before surgery the subjective disability in performing visually dependent tasks (the disability index) is significantly correlated with the visual acuity of the better eye. Third, after surgery there is a statistically significant correlation between the improvement in the subjective ability to perform visually dependent tasks and the increase in VA of the operated eye as well as the better eye. Fourth, it is possible to use rather simple questions in a short-form questionnaire of visual ability and gain valid results.

The authors wish to express their sincere thanks to William Thorburn, MD, PhD, for assistance in formulating the questions of the questionnaires. We also thank the nursing staff of the Eye Clinic of Norrlands University Hospital, Umea, for help with the questionnaires. We are greatly indebted to Hans Stenlund, $\mathrm{PhD}$, Department of Epidemiology and Public Health, Umeå University, for statistical advice.

\section{References}

1. Lundström M, Stenevi U, Thorburn W. Assessment of waiting time and priority setting by means of a national register. Int J Technol Assess Health Care 1996;12:136-40.

2. Jay JL, Devlin ML. The increasing frequency of surgery for cataract. Eye 1990;4:127-31.

3. Batterbury M, Khaw PT, Hands R, Elkington AR. The cataract explosion: the changing pattern of diagnoses of patients attending an ophthalmic outpatient department. Eye 1991;5:369-72.

4. Jaffe NS. Glare and contrast: indications for cataract surgery. J Cataract Refract Surg 1986;12:372-5.

5. Mangione CM, Phillips RS, Seddon JM, Lawrence MG, Cook EF, Dailey $R$, et al. Development of the 'Activities of Daily Vision Scale': a'measure of visual functional status. Med Care 1992;30:1111-26.

6. Official Statistics of Sweden. Folkmängden 31 December 1992. Liber, Stockholm: National Central Bureau of Statistics, 1993.

7. Mönestam E, Wachtmeister L. Impact of cataract surgery on car driving: a population-based study in Sweden. Br J Ophthalmol 1997;81:16-22.

8. Stewart AL, Hays RN, Waew JE. The MOS Short-form General Health Survey: reliability and validity in a patient population. Med Care 1988;26:724-32.

9. Bernth-Petersen P. Visual function in cataract patients: methods of measurement and results. Acta Ophthalmol 1981;59:198-205. 
10. Steinberg EP, Tielsch JM, Schein OD, Javitt JC, Sharkey P, Cassard SD, et al. The VF-14: an index of functional impairment in patients with cataract. Arch Ophthalmol 1994;112:630-8.

11. Holladay JT, Prager TC. Mean visual acuity. Am J Ophthalmol 1991;111:372-4.

12. Javitt JC, Brenner MH, Curbow B, Legro MW, Street DA. Outcomes of cataract surgery: improvement in visual acuity and subjective visual function after surgery in the first, second and both eyes. Arch Ophthalmol 1993;111:686-91.

13. Sparrow JM, Ayliffe W, Bron AJ, Brown NP, Hill AR. Interobserver variability of the Oxford clinical cataract classification and grading system. Int Ophthalmol 1988;11:151-7.

14. Bergman B, Sjöstrand J. Vision and visual disability in the daily life of a representative population sample aged 82 years. Acta Ophthalmol (Copenh) 1992;70:33-43.

15. Lundström M, Fregell G, Sjöblom A. Vision related daily life problems in patients waiting for a cataract extraction. $\mathrm{Br} \mathrm{J}$ Ophthalmol 1994;78:608-11.

16. Desai P, Reidy A, Minassian DC, Validis G, Bolger J. Gains from cataract surgery visual function and quality of life. Br J Ophthalmol 1996;80:868-73.

17. Smiddy WE, Feuer W, Irvine D, Flynn HW, Blankenship GW. Vitrectomy for complications of proliferative diabetic retinopathy: functional outcomes. Ophthalmology 1995;102:1688-95.

18. Wormald RPL, Wright LA, Courtney P, Beaumont B, Haines AP. Visual problems in the elderly population and implications for services. BMJ 1992;304:1226-9.
19. Steinberg EP, Tielsch JM, Schein OD, Javitt JC, Sharkey P, Cassard SD, et al. National study of cataract surgery outcomes: variations in 4-month postoperative outcomes as reflected in multiple outcome measures. Ophthalmology 1994;101:1131-41.

20. Taylor RH, Misson GP, Moseley MJ. Visual acuity and contrast sensitivity in cataract: summation and inhibition of visual performance. Eye 1991;5:704-7.

21. McElvanney A, Moseley MJ, Jones HS. Binocular inhibition of visual performance in patients with cataract: the influence of test reliability. Acta Ophthalmol (Copenh) 1994;72:606-11.

22. Laidlaw DAH, Harrad RA, Hopper CD, Whitaker A, Donovan JL, Brookes ST, et al. Randomised trial of effectiveness of second eye cataract surgery. Lancet 1998;352:925-9.

23. Cataract Management Guidelines Panel. Cataract in adults: management of functional impairment. Clinical practice guideline no. 4. Rockville, MD: US Department of Health and Human Services, Public Health Service, Agency for Health Care Policy and Research, February 1993. AHCPR publication 93-0542.

24. Lumme P, Laatikainen L. Factors affecting the visual outcome after cataract surgery. Int Ophthalmol 1993;17:313-9.

25. Mönestam E, Wachtmeister L. The impact of cataract surgery on low vision patients: a population based study. Acta Ophthalmol Scand 1997;75:569-76.

26. Häkkinen L. Vision in the elderly and its use in the social environment. Scand J Soc Med Suppl 1984;3:5-60.

27. Applegate WB, Miller ST, Elam JT, Freeman JM, Wood TO, Gettlefinger TC. Impact of cataract surgery with lens implantation on vision and physical function in elderly patients. JAMA 1987;257:1064-6. 